\title{
An Exploration of Impact Factors Influencing Students' Reading Literacy in Singapore with Machine Learning Approaches
}

\author{
Xin Dong ${ }^{1} \& \mathrm{Jie} \mathrm{Hu}^{1}$ \\ ${ }^{1}$ Department of Linguistics and Translation, School of Linguistics and Translation, Zhejiang University, \\ Hangzhou, China \\ Correspondence: Jie Hu, Department of Linguistics and Translation, School of International Studies, Zhejiang \\ University, Hangzhou, 310058, China. E-mail: huj@zju.edu.cn
}

Received: July 10, 2019 Accepted: August 10, 2019 Online Published: August 26, 2019

doi:10.5539/ijel.v9n5p52 URL: https://doi.org/10.5539/ijel.v9n5p52

\begin{abstract}
This study identified the contextual factors which differentiated 15 -year-old students with high- and low-achieving reading literacy in Singapore based on Program for International Student Assessment (PISA) 2015. 4,015 students from Singapore were collected from the public dataset of PISA 2015, with 2,646 high-achieving students and 1,369 low-achieving students in PISA reading literacy test. The impact of the overall 49 contextual factors on reading literacy was analyzed in three levels: student level, family level and school level. Support vector machine (SVM), a machine learning approach, was applied to analyze these contextual features. It indicated that SVM could effectively distinguish these two cohorts of readers with an accuracy score of 0.78 . SVM-based recursive feature elimination (SVM-RFE), another machine learning approach, was then applied to rank these selected features. These features were outputted in descending order with regard to the degree of their significance to the differentiation. At last, an optimal set with 15 contextual factors was selected by RFE-CV (cross validation), which collectively affected the differentiation of students with high- and low-level of reading literacy. Based on the analysis, implications to further improving students' reading literacy can be achieved.
\end{abstract}

Keywords: contextual factors, reading literacy, support vector machine, PISA 2015

\section{Introduction}

Reading literacy refers to skills of reading, writing, comprehending, interpreting and discussing different texts in multiple situations in the context of Program for International Student Assessment (PISA), which is launched by the Organization for Economic Cooperation and Development (OECD) (OECD, 2010). Reading literacy can exert an impact on students' cognitive development (Kern \& Friedman, 2009), which is necessary for student to pursue high academic achievements. Therefore, excellent reading literacy is essential for students' future success (Smith, Mikulecky, Kibby, Dreher, \& Dole, 2000).

The importance of reading literacy for individuals brings the strong need to explore the factors that are related to students' excellent reading performance. The impact of different factors on students' reading performance has been widely studied (e.g., Carlisle, Correnti, Phelps, \& Zeng, 2009). Reading literacy is also becoming a focus of international macro-studies (OECD, 2010, 2013). As one of the most influential international macro-studies, PISA regularly assesses the 15-year-old students' literacy in reading, science and mathematics every three years worldwide. PISA offers rich data, including students' own factors, family situations and schools' information to explore the possible factors which affect students' academic performance (Fuchs \& Wößmann, 2008).

Compared with other students in PISA 2015, students in Singapore achieve the highest average mark in PISA 2015 reading literacy test. However, there are not sufficient researches focusing on the impact of contextual factors on students' reading literacy in Singapore. Therefore, it is essential to explore what contextual factors actually contribute to Singapore students' excellent reading performance in PISA 2015. This study aims to identify these factors and explore their influence on students' reading literacy.

\section{Literature Review}

Based on the PISA database, a large number of researches have been conducted to investigate the influence of different factors on students' reading literacy. As for contextual factors, related literature can be divided into three levels: student, family and school levels (e.g., Chen, Zhang, Wei, \& Hu, 2019). 


\subsection{The Influence of Student-Level Factors on Students' Reading Literacy}

There are numerous student-level factors influencing students' reading performance. In a large number of studies, student-level factors that generally affect readers' reading literacy mainly include gender, immigration status, learning time, affective domain factors and grade repetition status (e.g., Di Liberto, 2015; Fredrickson, 2001; Reeve, 2012).

Gender is a prominent indicator which influences students' reading performance. Studies show that gender difference can influence educational outcomes and the findings for reading literacy find that girls achieve better reading performance than boys in PISA studies (e.g., Reilly, 2012). In the case of Germany, researchers find that among 15-year-olds, girls outperform boys in reading performance. What's more, girls have more intrinsic motivation in reading and tend to read on their own initiative than boys (Schwabe, McElvany, \& Trendtel, 2015). Based on the database of PISA 2009, scholars find that females outperform males in reading performance by 21 points in Macao (Mak, Cheung, Soh, Sit, \& Ieong, 2016). All of these indicate that gender affects students' reading performance.

What's more, compared with native speakers, non-native speakers achieve lower reading literacy in PISA, which has always been a research focus. Studies focusing on immigrant students' academic achievement in Italy find that the first-generation immigrant students are likely to be influenced and immigration status may even affect the educational performance of the following generation through transmission mechanisms (Di Liberto, 2015). Through the investigation of the first-generation immigrant, students' reading score of this group is over 100 points lower than that of native students in Switzerland (Marks, 2005). However, Lenkeit, Caro and Strand (2015) conduct a research in England and find that those immigrants who have poor reading literacy generally come from families with inferior socioeconomic status, which indicates that the relatively low reading literacy of non-native speakers is not only caused by their immigration status but also by their poor socioeconomic status.

Apart from gender and immigration status, reading engagement has always attracted researchers' attention in recent years because of its influence on students' academic achievements (e.g., Chen \& Hu, 2018). Students who are highly engaged in reading tend to spend more time on it and achieve high performance (e.g., Xiao \& $\mathrm{Hu}$, 2019c). Individuals who are self-determining in pursuing higher performance could achieve better development than their counterparts (OECD, 2010), and those who have good autonomy are intrinsically motivated to read widely (Reeve, 2012). In addition, self-efficacy has also been explored and it is related to students' high academic performance. Students with high self-efficacy may be more positive in academy engagement (Areepattamannil, Freeman, \& Klinger, 2010; Chang, 2015; Chen \& Hu, 2019). What's more, interest and enjoyment are two correlated factors (Fredrickson, 2001). Together with interest in reading, the enjoyment of reading is also closely related to good academic performance (Areepattamannil et al., 2010; Wei \& Hu, 2019). Apart from these factors in affective domain, related findings also indicate that higher socioeconomic status is correlated with lower probability of repetition (e.g., Ferrão, Costa, \& Matos, 2017), which would thus influence students' academic achievements.

\subsection{The Influence of Family-Level Factors on Students' Reading Literacy}

Home environment is of great significance in the acquisition of reading literacy and this positive relation may benefit the development of reading literacy (e.g., Epstein, 2018). The impact of the family is regarded as a powerful factor in students' academic performance (e.g., Farver, Xu, Eppe, \& Lonigan, 2006). The role of families has always been emphasized in acquiring reading ability (Ngorosho, 2010). Moreover, researches which analyze the influence of the family environment on students' reading literacy in developing countries achieve similar positive results (Aram \& Levin, 2002; Ngorosho, 2010).

Family-level factors include the economic, social and cultural status of families (SES), parents' education levels, occupational status, communications technology (ICT) resources and educational resources at home. Family SES status can be represented by various household resources. Ho (2010) emphasizes that cultural resources are positively related to students' performance in Hong Kong. Topçu, Arıkan and Erbilgin (2014) point out that good economic status and a great deal of resources would impose good influence on students' academic performance. In families with low economic income, low-level of parental education, and few possessions, students tend to have lower reading literacy and poorer academic achievement than students from families with superior economic status (Farver et al., 2006). Similarly, students from families with a low wealth index may suffer from low self-esteem and a disadvantaged environment, which would affect their academic performance (Blacksher, 2002). In PISA 2009, countries with greater wealth obtain better reading scores than their counterparts (OECD 2010). As for cultural resources at home, parents can help children read from an early age. Therefore, families with few cultural resources like books can hardly support students' reading literacy development. Heckman 
(2011) suggests that a good solution to this issue is to offer the necessary resources to disadvantaged families so as to narrow the gap.

Moreover, the influence of ICT on students' performance has attracted people's attention in recent years (e.g., Fuchs \& Wößmann, 2006). Skryabin, Zhang, Liu and Zhang (2015) find that ICT use at school would lower students' enthusiasm and thus harm students' academic performance, while ICT use at home could help students improve their academic achievement. Petko, Cantieniand and Prasse (2016) find similar results. Hu et al. (2018) also find that in schools where ICT is used, students achieve lower academic performance. These studies indicate that there are some different viewpoints regarding to the influence of having access to ICT at home and at school, which is worth further exploring (Hu, Gong, Lai, \& Leung, 2018; Seneviratne, De Silva, Hu, \& Beveridge, 2019).

\subsection{The Influence of School-Level Factors on Students' Reading Literacy}

A great number of researches have revealed that school-level context is an influential factor in improving students' reading literacy (e.g., Farver et al., 2006). Generally, the school context that impact students' reading literacy can be analyzed through the following factors: school type, school size, school economic status, principal leadership, teacher participation, teachers' qualification, and ICT resources at school (Rutter \& Maughan, 2002; Shin, Slater, \& Ortiz, 2017).

School type is a significant factor in school-context and it has been discussed in the educational field in recent years. In some studies, public schools are viewed as input-oriented organizations, which have no initiative to innovate and are reluctant to the demand of students and teachers (e.g., Jehangir, Glas, \& Van den Berg, 2015). By contrast, private schools enjoy more freedom and innovations since they can get rid of the bureaucracy and rigid regulations (e.g., Lee \& Burkam, 2003). Apart from school type, many studies have been conducted to show how school size affects student achievement and find that in primary schools, small schools contribute more to higher students' academic performance than large schools (Giambona \& Porcu, 2018). School socioeconomic status is also strongly correlated with students' performance. Students in schools with better economic situation may get higher attainment. In addition, some school practices could effectively narrow students' performance gap (Rutter \& Maughan, 2002).

What's more, the impact of principal leadership on student performance is worth exploring (Leithwood \& Day, 2008; Leithwood \& Hopkins, 2008). A host of school variables that affect school capacity have been identified: improved instruction, professional development, shared governance, support of teachers and teacher attitude. Support from teachers in emotion and action may greatly affect students' attitude. With teachers' help, students can get over difficulties more easily and they would be more confident, so their enthusiasm to learn can be promoted (Hu, 2014; Shin, Slater, \& Ortiz, 2017). In addition, students who receive timely feedback of teachers tend to get better academic performance (Chen et al., 2019). Moreover, there is a general agreement that teacher quality may affect students' academic performance (Hu \& Wei, 2019; Meng, Muñoz, King Hess, \& Liu, 2016; Nie \& $\mathrm{Hu}, 2018$,). One dimension of the effective teaching model also emphasizes teachers' quality including knowledge of teaching and learning, certificate status, and teaching experience (Chen et al., 2019).

\subsection{Research Questions}

Since few researches focus on contextual factors impacting students' reading literacy in Singapore, this study narrows the gap by exploring the influence of student-, family- and school-level factors on high- and low-performing students with machine learning methods. Two research questions are addressed in this study:

(1) Can contextual factors differentiate 15 -year-old students with high-level reading literacy from those with low-level reading literacy in Singapore? If so, what are they?

(2) Which contextual factors that influence students' high- and low-level of reading literacy in Singapore are included in the optimal feature set?

\section{Materials and Methods}

\subsection{Sample}

The samples were selected based on the latest PISA 2015 database, which was published by OECD. Among the students from 72 countries and economies participating in PISA 2015, students in Singapore achieved the highest average mark (535) in the PISA reading literacy test. This meant that Singapore outperformed the rest of the participated countries and economies in this survey regarding to students' reading literacy. In this case, Singapore was selected as the sampling country to identify contextual factors. According to PISA 2015 dataset, there were 47,050 enrolled 15-year-olds in Singapore. The extreme levels of students had more typical 
characteristics than intermediate students (e.g., Chen et al., 2019). Therefore 4,015 students (2,646 high-achieving students and 1,369 low-achieving students) who finished the related PISA 2015 questionnaires were chosen as the sample in this study.

\subsection{Variables}

The dichotomous dependent variables were reading scores of the students with high- and low-level reading performance, whose reading scores were higher than 550 and lower than 400 respectively. The independent variables were chosen from the target questionnaires in PISA 2015. An overall of 49 factors (see Table 1) related to students' reading performance were identified from the PISA dataset and were divided into three levels in this study: student-level factors included immigration status, learning time of test language and study time out-of-school, attitude towards cooperation, motivation and repetition status; family-level factors included parents' education level, home possessions about culture and wealth, whole economic and social status of family and ICT at home; and school-level factors referred to school size, class size, school ownership, principals' leadership, school climate, teachers' participation, instruction, quality and feedback, and various resources at school.

Table 1. The overall 49 variables and their descriptions in PISA 2015 (OECD, 2017)

\begin{tabular}{|c|c|c|c|}
\hline Variable & Description & Variable & Description \\
\hline \multicolumn{4}{|c|}{ Student-level variables (9) } \\
\hline LMINS & $\begin{array}{l}\text { Learning time (minutes per week) }-<\text { test } \\
\text { language }>\end{array}$ & INSTSCIE & Instrumental motivation \\
\hline OUTHOURS & Out-of-school study time per week & MOTIVAT & Achieving motivation \\
\hline COOPERATE & Enjoy cooperation & IMMIG & Immigration status \\
\hline CPSVALUE & Value cooperation & REPEAT & Grade repetition \\
\hline W_FSTUWT & $\begin{array}{l}\text { FINAL TRIMMED NONRESPONSE } \\
\text { ADJUSTED STUDENT WEIGHT }\end{array}$ & & \\
\hline \multicolumn{4}{|c|}{ Family-level variables (13) } \\
\hline MISCED & Mother's education (ISCED) & WEALTH & Family wealth \\
\hline FISCED & Father's education (ISCED) & ICTRES & ICT Resources \\
\hline PARED & Highest education of parents in years & HOMEPOS & Home possessions \\
\hline CULTPOSS & Cultural possessions at home & ESCS & Index of economic, social and cultural status \\
\hline HEDRES & Home educational resources & hisei & Highest parental occupational status \\
\hline EMOSUPS & Parents emotional support & ICTHOME & ICT available at Home Index (Sum) \\
\hline ICTSCH & ICT available at School Index (Sum) & & \\
\hline \multicolumn{4}{|c|}{ School-level factors (27) } \\
\hline SCHSIZE & School Size & SCHAUT & School autonomy \\
\hline CLSIZE & Class Size & SCHLTYPE & School Ownership \\
\hline RATCMP1 & Index of computer availability & EDUSHORT & Shortage of educational material \\
\hline RATCMP2 & Index of computers connected to the Internet & STAFFSHORT & Shortage of educational staff \\
\hline LEAD & Educational leadership & TOTAT & Total number of all teachers at school \\
\hline LEADCOM & Curricular development & STRATIO & Student teacher ratio \\
\hline LEADINST & Instructional leadership & CREACTIV & Creative extra-curricular activities \\
\hline LEADPD & Professional development & STUBEHA & $\begin{array}{l}\text { Student-related factors affecting school } \\
\text { climate }\end{array}$ \\
\hline LEADTCH & Teachers participation & TEACHBEHA & $\begin{array}{l}\text { Teacher-related factors affecting school } \\
\text { climate }\end{array}$ \\
\hline RESPCUR & Responsibility for curriculum & PERFEED & Perceived feedback \\
\hline RESPRES & Responsibility for resources & ADINST & Adaption of instruction \\
\hline TEACHPART & Teacher participation & PROATCE & Proportion of all teachers fully certified \\
\hline PROAT5AB & $\begin{array}{l}\text { Proportion of all teachers ISCED LEVEL 5A } \\
\text { Bachelor }\end{array}$ & PROAT5AM & $\begin{array}{l}\text { Proportion of all teachers ISCED LEVEL 5A } \\
\text { Master }\end{array}$ \\
\hline PROAT6 & Proportion of all teachers ISCED LEVEL 6 & & \\
\hline
\end{tabular}

\subsection{SVM Modelling}

Machine learning approaches have already been applied in many academic fields including statistics and computational sciences (e.g., Cui et al., 2019; Li et al., 2019). Scholars are still exploring the application of machine learning approaches in more fields, for example, in education (e.g., Jing, $\mathrm{Li}$, Chen, $\mathrm{Li}, \& \mathrm{Hu}, 2015$; Wei, Yang, Chen, \& Hu, 2018). While these approaches have not been commonly used in humanities and social sciences researches, where the combination of quantitative and qualitative analysis is generally applied (e.g., Chen et al., 2019; Xiao, $\mathrm{Li}, \& \mathrm{Hu}, 2019)$. SVM is a supervised machine learning approach. It constructs a model dealing with input with different labels and outputting data so that it can predict future situations (Jordan \& 
Mitchell, 2015). When classifying input data, SVM provides the excellent and efficient classification by constructing an optimal theoretical hyperplane, which can separate two groups of multidimensional descriptors (Cortes \& Vapnik, 1995). As an artificial intelligence algorithm, SVM stands out in binary classification with high accuracy and robustness (Chen et al., 2019). In particular, it is an outstanding technique in mapping data with complex variables in multiple dimensions (Cui et al., 2019). Therefore, SVM was applied in this study since it could classify the target data with high accuracy regarding its excellent classification ability.

SVM aims to identify the optimal hyperplane to classify two cohorts of objects (Chen et al., 2019). According to previous studies, the current study utilized LIBSVM (Chang \& Lin, 2011), a software package which made it easy to access SVM for free. The SVM model is constructed in two steps: First, selecting a train data set $\left(\mathrm{x}_{\mathrm{i}}\right.$, $\left.\mathrm{y}_{\mathrm{i}}\right), \mathrm{x}_{\mathrm{i}} \in \mathrm{Rd}, \mathrm{y}_{\mathrm{i}} \in\{+1,-1\}, i=1,2, \ldots, \mathrm{n}$; Second, choosing two labels standing for the two cohorts of descriptors, for example, class A and class B. In this study, they referred to students with high-level and low-level reading literacy respectively. The hyperplane is written as $w_{x}+b=0$ ( $w$ is the weight vector and $b$ is the bias). The hyperplane should satisfy the equation:

$$
y_{i}\left(w x_{i}+b\right) \geq 1
$$

Training data which fulfill the equation (1) are called support vectors. In this case, the optimal hyperplane can be identified by satisfying equation (1) and minimum $1 / 2 \mathrm{w}^{2}$. The chosen hyperplane should keep the same distance from support vectors from these two cohorts. The data with support vectors in two-dimensional space are presented as shown in Figure 1.

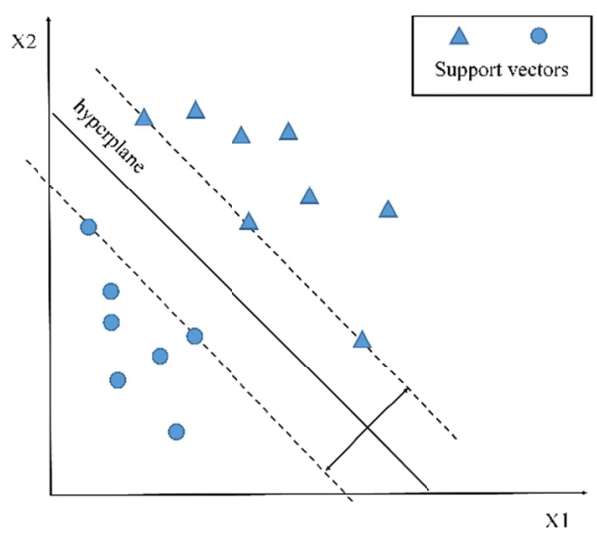

Figure 1. Support vector machine model in two-dimensional space

When the samples cannot be separated by a line, the non-linear kernel function included in SVM can be utilized. Its function is to distribute the target data to the high-dimensional space, so that to achieve the optimal hyperplane (Chen et al., 2019). The process is presented in Figure 2.

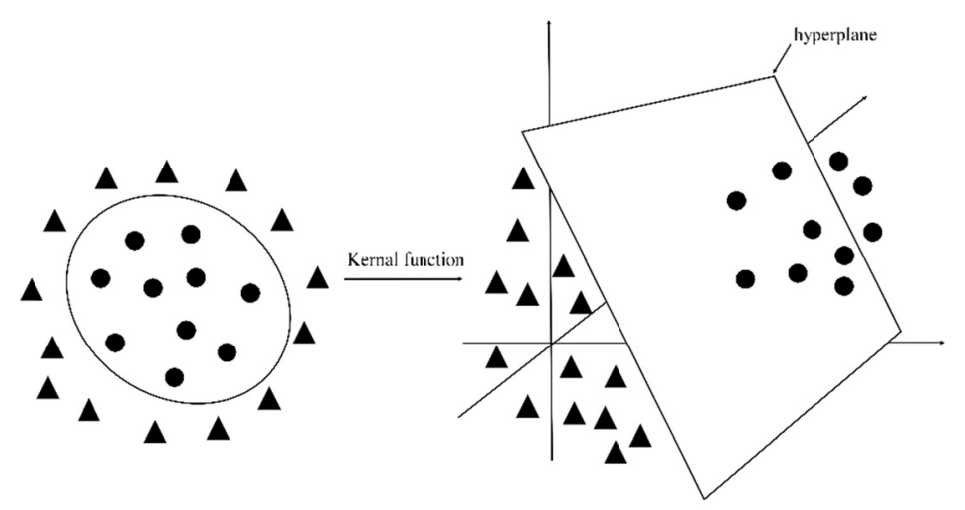

Figure 2. Support vector machine model using the kernel function 
In this model, SVM-recursive feature elimination (SVM-RFE) is an important approach to select features according to their degree of significance to differentiation (Guyon, Weston, Barnhill, \& Vapnik, 2002; Jin et al., 2015; Xiao, Liu, \& Hu, 2019). The feature with the smallest significance is removed each time. At last, the SVM-RFE model would output a ranking list of these features in descending order according to the significance of each feature to the binary classification of the model.

Different feature sets contribute differently to the classification effect of the model. In order to obtain the features with noteworthy significance, it is essential to implement RFE-cross validation (RFE-CV), which can measure different feature sets and identify the optimal one with the best collective effect on classification. During RFE-CV process, a k-fold cross-validation is implemented, which divides the whole dataset into k parts. Similarly, SVM constructs a statistical model of data to explore the relationships between training data and target data, so that to identify the relations between variables (Chen et al., 2019). In the model, the key indicator of the model performance is the rate of accuracy. The equation to account the score of this indicator is shown as follows:

$$
\text { Accuracy }=(T N+T P) /(T P+T N+F P+F N)
$$

Where:

TP (true positive) refers to the number of objects in class A correctly classified;

TN (true negative) refers to the number of objects in class B correctly classified;

FP (false positive) refers to the number of objects in class A incorrectly classified;

FN (false negative) refers to the number of objects in class B incorrectly classified.

\subsection{Data Analysis Procedure}

The first step to analyze data was to implement data preprocessing, which included four steps: cleaning, imputation, integration, and normalization. During this process, raw data were firstly preprocessed by deleting some $(\mathrm{N}=20)$ samples with missing values in more than half columns. Then data imputation was dealt with using the mean value of nearest-neighbor (Gorostiaga \& Rojo-Álvarez, 2016). After that, variables in student-level and school-level were integrated according to student ID. Finally, data normalization was carried out with the centering and variance scaling principle.

After data preprocessing, the publicly free computing program Python 3.5 was used to conduct a three-step statistical analysis. First, the overall 49 features were inputted into the SVM model to identify whether students with high- and low-levels of reading literacy could be distinguished with these contextual features. Then SVM-RFE was used to sort the 49 contextual factors with regard to their significance degree to the classification and these factors were outputted in descending order. At last, through the RFE-CV (Sanz, Valim, Vegas, Oller, \& Reverter, 2018), a 10-fold cross-validation method was applied to identify the optimal feature set with the greatest contribution and the minimal number of features. At the same time, the optimal set of features was output in visualization.

\section{Results and Discussion}

\subsection{Results}

In this study, an accuracy score of 0.78 was achieved with the SVM model, indicating that the selected contextual features could effectively differentiate 15-year-old students with high- and low-levels of reading performance.

To identify the significance degree of features in distinguishing students' high- and low-level of reading literacy, SVM-RFE outputted a descending ranking list of the chosen features with reference to the different contribution of these features to the classification. Then RFE-CV was applied to identify the accuracy scores of different feature sets. According to the study by Gorostiaga and Rojo-Álvarez (2016), around 20 features can compose the best set in PISA studies. Therefore, the following 4 feature sets of top 10, top 15, top 20 and top 25 features were adopted in the SVM model to calculate their mean accuracy score. Then the top 15 features were selected as the optimal feature set with prediction accuracy of 0.7736 , comparing with that of the top $10(0.7688)$, top 20 (0.7736) and top25 (0.7658) (see Table 2). 
Table 2. Prediction accuracy of the four possible feature sets by 10 -fold cross-validation

\begin{tabular}{ll}
\hline Possible optimal feature sets & Mean accuracy rates \\
\hline Top-10 features & 0.7688 \\
Top-15 features & 0.7736 \\
Top-20 features & 0.7668 \\
Top-25 features & 0.7658 \\
\hline
\end{tabular}

The result can also be verified by the plot. As shown in Figure 3, when top-15 features were analyzed in this model, the curve reached the highest point with an accuracy score of 0.7736 . In this case, these 15 features were included in the optimal set with the highest accuracy score and the minimum features. Therefore, the top-15 features can best differentiate readers with high- and low-level of reading literacy.

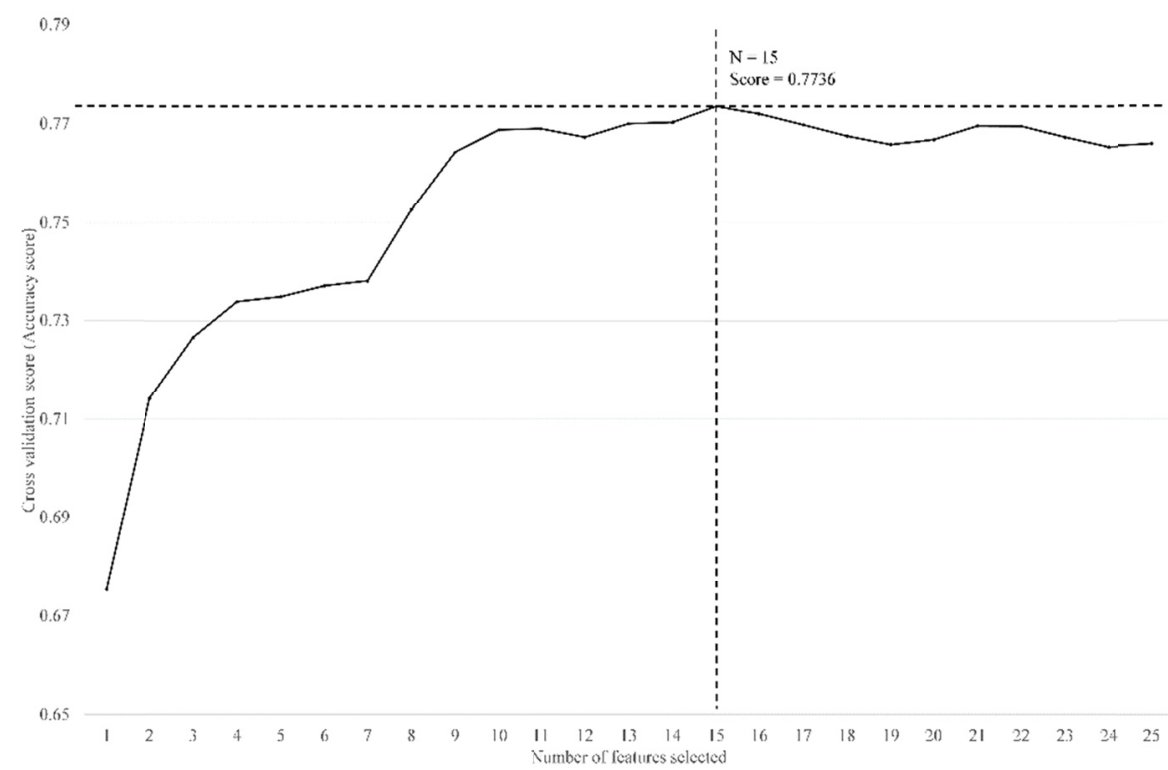

Figure 3. The accuracy values of different feature sets by the RFE-CV method

Moreover, it was necessary to calculate the mean value and standard derivation value to add statistics about the key features respectively, revealing possible trend and influence. Table 2 displayed these 15 features that were listed in descending order with regard to their contribution to classification.

Table 3. Top-15 target features with their descriptions, value range, mean value (M) and standard deviation (SD)

\begin{tabular}{lllll}
\hline Rank & Feature & Description & $\begin{array}{l}\text { Value range } \\
\text { (Min. } \sim \text { Max.) }\end{array}$ & M (SD) \\
\hline 1 & ESCS & Index of economic, social and cultural status & $-4.05 \sim 3.50$ & $0.02(0.93)$ \\
2 & LMINS & Learning time (minutes per week) $-<$ test language $>$ & $0.00 \sim 1700.00$ & $256.89(135.92)$ \\
3 & SCHSIZE & School Size & $332.00 \sim 4130.00$ & $1193.00(475.06)$ \\
4 & HOMEPOS & Home possessions & $-4.74 \sim 5.12$ & $-0.12(0.94)$ \\
5 & WEALTH & Family wealth & $-4.77 \sim 4.08$ & $-0.20(0.86)$ \\
6 & CULTPOSS & Cultural possessions at home & $-1.71 \sim 2.56$ & $-0.15(0.98)$ \\
7 & ADINST & Adaption of instruction & $-1.97 \sim 2.05$ & $0.43(0.87)$ \\
8 & PERFEED & Perceived feedback & $-1.53 \sim 2.50$ & $0.32(0.89)$ \\
9 & CPSVALUE & Value cooperation & $-2.83 \sim 2.10$ & $0.25(1.03)$ \\
10 & COOPERATE & Enjoy cooperation & $-3.33 \sim 2.29$ & $0.32(1.02)$ \\
11 & REPEAT & Grade repetition & $0.00 \sim 1.00$ & $0.06(0.24)$ \\
12 & ICTHOME & ICT available at Home Index (Sum) & $0.00 \sim 11.00$ & $7.95(1.92)$ \\
13 & PROAT6 & Proportion of all teachers ISCED LEVEL 6 & $0.00 \sim 0.11$ & $0.007(0.015)$ \\
14 & LEADTCH & Teachers participation & $-2.07 \sim 2.40$ & $-0.03(0.91)$ \\
15 & LEADINST & Instructional leadership & $-1.68 \sim 2.23$ & $0.3(0.78)$ \\
\hline
\end{tabular}




\subsection{Student-Level Factors Related to Students' Literacy}

In this study, there were four effective factors related to students themselves influencing students' reading performance. The learning time that students spent on test language (LMINS) was a strong indicator of high- and low-achieving readers. Generally, students' learning time could be extended to homework and other extracurricular activities (Xiao \& $\mathrm{Hu}, 2019 \mathrm{a}$ ). Caution was paid to the learning time on test language per week within school, which was a significant feature to distinguish high- and low-level readers. In this study, students with high-achieving reading literacy tended to spend more time on learning test language per week. According to Jin et al. (2016), learning time in school was an important factor for high-achieving readers. Previous researches have also revealed that learning time at school and at other study-related tasks could exert great influence on students' performance (Lee \& Burkam, 2003; McCluskey, Bynum, \& Patchin, 2004).

Apart from learning time, factors in affective domain were also important. Students' aptitude referred to affective behavioral features of readers in the reading process, including interest in reading, attitude towards cooperation (CPSVALUE) and other reading practices (McKenna, Kear, \& Ellsworth, 1995). Studies have shown that fully engaged readers can grasp the key points of texts and effectively command the whole meaning. Therefore, these students achieved better academic performance (Esther \& Lau, 2018; Wei \& Hu, 2018b). Other studies also confirmed that students with higher self-efficacy could get higher academic performance (Lam \& Lau, 2014). By contrast, many low-performing students generally had cognitive drawbacks and lacked motivation to reading (Hertz et al., 2008). In this study, students who hold positive attitude towards cooperation and enjoy cooperation (COOPERATE) tended to achieve better reading performance, which was consistent with findings of other studies. In this case, students' attitude towards cooperation is a strong indicator to differentiate their reading literacy.

In addition, grade repetition (REPEAT) could post negative influence on students' reading literacy. In this study, the results showed that students who did not repeat a grade performed better than those who repeated a grade, which was confirmed by other scholars (e.g., Areepattamannil et al., 2010). It was also found that a lower socioeconomic status was related to a higher probability of repetition, which also affected students' reading performance (Lee \& Burkam, 2003). Moreover, the socioeconomic composition and the school proportion of repeaters had a strong influence on the individual probability of repetition, which may exacerbate students' social disadvantage (Ferrão et al., 2017).

\subsection{Family-Level Factors Related to Students'Reading Literacy}

In family-level, factors influencing students' reading literacy included the overall economic, social and cultural status (ESCS), cultural possessions at home (CULTPOSS), home possessions (HOMEPOS), family wealth (WEALTH) and ICT available at Home (ICTHOME).

ESCS was the most important factor in this study since it ranked first in the selected 15 features, which included general descriptions of parents' education level, parents' occupational status and home possession status. A mass of studies have shown that socioeconomic status could greatly affect students' academic achievement (e.g., Cabrera \& La Nasa, 2000). According to Coleman (2018), students' background was the most influential factor in their studies. Other related researches also provided solid evidence that the high academic achievement of students was closely related to their superior economic background (e.g., Sirin, 2005; White, 1982). Moreover, researchers have identified that if students suffer from inferior economic family status, they might be affected in a quite long period even when they grow up (Alexander, Entwisle, \& Olson, 2007; Cabrera \& La Nasa, 2000).

In addition to the overall effect of socioeconomic status, parents' education levels were associated with children's academic performance, since well-educated parents were role models for their children and they could offer children more resources and instructions (Burhan et al., 2017; Epstein, 2018). What's more, parents' occupational status could affect students' academic performance and abilities (Gorostiaga \& Rojo-Álvarez, 2016). It has been found that in families where parents have accepted good education and with relatively high occupational status, children are likely to get similar achievement (Hertz et al., 2008). This study also found similar trend in Singapore.

In families, cultural possession (CULTPOSS) included the number of books of poetry, books on art, music, designs and works of art at home. In this study, it was found that high index of cultural possession was associated with higher reading literacy. In particular, parents in Singapore are influenced by Confucian values and a lasting belief that academic achievement come from hard working. This deeply affects parents' attitude towards education and thus influences students' academic performance (Hofstede \& Bond, 1988; Perera \& Asadullah, 2019; Xiao \& Hu, 2019c). In this study, other home possessions like a desk that students can use and a quiet place to study (included in HOMEPOS), televisions, cars, smartphones, portable laptops and musical 
instruments (belonged to WEALTH) were also found associated with students' reading literacy, which were consistent with previous study (Ngorosho, 2010). What's more, ICT available at home (ICTHOME) including desktop computers, Internet connection, printers were also a strong indicator of students with high reading literacy (Hu, Gong, Lai, \& Leung, 2018, Xiao \& Hu, 2019b, 2019c).

\subsection{School-Level Factors Related to Students'Reading Literacy}

In this study, six school-level factors which affected students' reading literacy were identified: The total enrolment of schools (SCHSIZE), instructional leadership of principal (LEADINST), teacher participation (LEADTCH), teachers' feedback (PERFEED), teachers' adaption of instruction (ADINST) and the proportion of high-quality teachers (PROAT6).

The total enrolment of schools (SCHSIZE) was associated with students' performance, which was consistent with other studies (Chen et al., 2019; Rutter \& Maughan, 2002). In the PISA 2009 reading test, students in schools with more than $60 \%$ girls performed better than boys in reading tests (Van Hek, Kraaykamp, \& Pelzer, 2017).

Instructional leadership meant that principals managed to motivate teachers to improve teaching quality (LEADINST). The relationship between student performance and instructional leadership of principal is always a focus of researchers (e.g., Leithwood \& Day, 2008). In this study, in schools where principals managed to motivate teachers to improve teaching quality, students performed better in PISA 2015 test. A number of studies indicated that the leadership role of the principal was more important than other contextual factors in school, which contributed to students' achievement (Ho \& Lau, 2018; Shin, Slater, \& Ortiz, 2017; Wei \& Hu, 2018a). Teacher participation (LEADTCH) referred to principals offering opportunities to teachers to manage school affairs. In Singapore, principals and teachers are given more autonomy in school affairs. Schools can learn from others and become more innovative in their curriculum and teaching process (Poon et al., 2016). Moreover, principals decide school budget, teacher enrolment and curriculum innovations etc. (Perera \& Asadullah, 2019), and teachers enjoy more opportunities to participate in school affairs.

Considering principals' guide, teachers managed to change their instructions with students' actual needs (ADINST) in many lessons and thus improved students' reading performance. In teaching process, designing classes according to students' interests and need was effective in cultivating high-achieving readers (Xiao \& Hu, 2019a). Moreover, appropriate materials might help students to foster intrinsic motivation and motivate them to participate extrinsic engagement (Johnson \& Blair, 2003; Xiao \& Hu, 2019a). What's more, excellent readers usually received teacher feedback (PERFEED) during their learning process. They could reflect on their past studies and get their reading performance improved (Shin, Slater, \& Ortiz, 2017).

In addition, schools with more teachers equipped with an ISCED Level 6 qualification (PROAT6) did better in cultivating high-achieving performers than those with low proportion of high-quality teachers, which was in accordance with related studies (Leithwood \& Hopkins, 2008; Meng et al., 2016). Schools with a large proportion of college-educated teachers achieved better scores in the PISA 2009 reading test (Van Hek et al., 2017). Singapore does well in attracting high-quality teachers and teachers are regarded as the core of educational system in Singapore. Enrolled teachers enjoy a high status since Confucian-heritage societies like Singapore possess great respect for teachers (OECD, 2011). Singapore can enroll top graduates into the teaching profession and only the best one-third students can enter the teacher training institute (Sclafani, 2005). After participating initial pre-service programs at the National Institute of Education (NIE), teachers should continually improve their abilities through other trainings (Poon et al., 2016).

What's more, since English is the official language in Singapore, the government has made efforts to help students with low-level performance. It consistently provides reading support programs to help students who lag behind to improve their reading literacy (Curdt-Christiansen \& Silver, 2012; Wolf \& Bokhorst-Heng, 2008). All of these efforts promote the development of an open and collaborative learning environment for students in Singapore (Poon et al., 2016).

\section{Conclusion}

In recent decades, Singapore has made significant achievements in cultivating talents (OECD, 2010), which has attracted scholars' attention worldwide. The purpose of this study is to explore contextual factors that differentiated 15-year-old students with high- and low-level reading literacy in Singapore based on PISA 2015 database. In this study, SVM was used to identify the optimal feature set of contextual factors, which offered a meaningful perspective to analyze the collective effect of contextual factors. These features were categorized into three levels: student level, family level and school level, which was consistent with previous studies (e.g., 
Alivernini et al., 2016). In this study, 15 features included in the optimal set were selected in the classification process and collectively affected students' reading literacy. In conclusion, this study reveals the collective impact of contextual factors on students' reading literacy in Singapore, bringing educational implications for future studies.

\section{Acknowledgments}

Authors gratefully acknowledge the research project supported by the Philosophical and Social Sciences Planning Project of Zhejiang Province in 2020 (Grant Number: 20NDJC01Z).

\section{References}

Alexander, K. L., Entwisle, D. R., \& Olson, L. S. (2007). Lasting consequences of the summer learning gap. American Sociological Review, 72(2), 167-180. https://doi.org/10.1177/000312240707200202

Alivernini, F., Manganelli, S., \& Lucidi, F. (2016). The last shall be the first: Competencies, equity and the power of resilience in the Italian school system. Learning and Individual Differences, 51, 19-28. https://doi.org/10.1016/j.lindif.2016.08.010

Aram, D., \& Levin, I. (2002). Mother-child joint writing and storybook reading: Relations with literacy among low SES kindergartners. Merrill-Palmer Quarterly, 48(2), 202-224. https://doi.org/10.1353/mpq.2002.0005

Areepattamannil, S., Freeman, J. G., \& Klinger, D. A. (2010). Influence of motivation, self-beliefs, and instructional practices on science achievement of adolescents in Canada. Social Psychology of Education, 14(2), 233-259. https://doi.org/10.1007/s11218-010-9144-9

Blacksher, E. (2002). On being poor and feeling poor: Low socioeconomic status and the moral self. Theoretical Medicine, 3, 455-470. https://doi.org/10.1023/A:1021381616824

Cabrera, A. F., \& La Nasa, S. M. (2000). Three critical tasks America's disadvantaged face on their path to college. New Directions for Institutional Research, 2000(107), 23-29. https://doi.org/10.1002/ir.10702

Carlisle, J. F., Correnti, R., Phelps, G., \& Zeng, J. (2009). Exploration of the contribution of teachers' knowledge about reading to their students' improvement in reading. Reading and Writing, 22(4), 457-486. https://doi.org/10.1007/s11145-009-9165-y

Chen, J., \& Hu, J. (2018). Enhancing L2 learners' critical thinking skills through a connectivism-based intelligent learning system. International Journal of English Linguistics, 8(6), 12-21. https://doi.org/10.5539/ijel.v8n6p12

Chen, J., Zhang, Y., Wei, Y., \& Hu, J. (2019). Discrimination of the contextual features of top performers in scientific literacy using a machine learning approach. Research in Science Education. Retrieved from https://rdcu.be/btN56. https://doi.org/10.1007/s11165-019-9835-y,

Chen, X., \& Hu, J. (2019). Evolution of U.S. presidential discourse over 230 Years: A psycholinguistic perspective. International Journal of English Linguistics, 9(4), 28-41. https://doi.org/10.5539/ijel.v9n4p28

Chen, X., Yan, Y., \& Hu, J. (2019). A corpus-based study of Hillary Clinton's and Donald Trump's linguistic styles. International Journal of English Linguistics, 9(3), 13-22. https://doi.org/10.5539/ijel.v9n3p13

Coleman, J. S. (2018). Redesigning American Education. Taylor \& Francis Group. https://doi.org/10.4324/9780429497766-2

Cortes, C., \& Vapnik, V. (1995). Support-vector networks. Machine Learning, 20(3), 273-297. https://doi.org/10.1007/BF00994018

Cui, X. J., Yang, Q. X., Li, B., Tang, J., Zhang, X. Y., Li, S., Li, F. C., Hu, J., Lou, Y., Qiu, Y. Q., Xue, W. W., \& Zhu. F. (2019). Assessing the effectiveness of direct data merging strategy in long-term and large-scale pharmacometabonomics. Frontiers in Pharmacology, 10, 127. https://doi.org/10.3389/fphar.2019.00127

Curdt-Christiansen, X. L., \& Silver, R. E. (2012). Educational reforms, cultural clashes and classroom practices. Cambridge Journal of Education, 42(2), 141-161. https://doi.org/10.1080/0305764X.2012.676631

Di Liberto, A. (2015). Length of stay in the host country and educational achievement of immigrant students. International Journal of Manpower, 36(4), 585-618. https://doi.org/10.1108/JJM-11-2013-0261

Epstein, J. L. (2018). School, family, and community partnerships, student economy edition: Preparing educators and improving schools. Taylor \& Francis Group. https://doi.org/10.4324/9780429493133-3

Farver, J. A., Xu, Y., Eppe, S., \& Lonigan, C. J. (2006). Home environments and young Latino children's school 
readiness. Early Childhood Research Quarterly, 21(2), 196-212. https://doi.org/10.1016/j.ecresq.2006.04.008

Ferrão, M. E., Costa, P. M., \& Matos, D. A. (2017). The relevance of the school socioeconomic composition and school proportion of repeaters on grade repetition in Brazil: A multilevel logistic model of PISA 2012. Large-scale Assessments in Education, 5(1). https://doi.org/10.1186/s40536-017-0036-8

Fredrickson, B. L. (2001). The role of positive emotions in positive psychology: The broaden-and-build theory of positive emotions. American Psychologist, 56(3), 218-226. https://doi.org/10.1037/0003-066X.56.3.218

Fuchs, T., \& Wößmann, L. (2006). What accounts for international differences in student performance? A re-examination using PISA data. Empirical Economics, 32(2-3), 433-464. https://doi.org/10.1007/s00181-006-0087-0

Fuchs, T., \& Wößmann, L. (2008). What accounts for international differences in student performance? A re-examination using PISA data. The Economics of Education and Training, 209-240. https://doi.org/10.1007/978-3-7908-2022-5_10

Giambona, F., \& Porcu, M. (2018). School size and students' achievement. Empirical evidences from PISA survey data. Socio-Economic Planning Sciences, 64, 66-77. https://doi.org/10.1016/j.seps.2017.12.007

Gorostiaga, A., \& Rojo-Álvarez, J. L. (2016). On the use of conventional and statistical-learning techniques for the analysis of PISA results in Spain. Neurocomputing, 171, 625-637. https://doi.org/10.1016/j.neucom.2015.07.001

Guyon, I., Weston, J., Barnhill, S., \& Vapnik, V. (2002). Gene selection for cancer classification using support vector machines. Machine Learning, 46, 389-422. https://doi.org/10.1023/A:1012487302797

Heckman, J. (2011). The American family in black and white: A post-racial strategy for improving skills to promote equality. Daedalus, 140(2), 70-89. https://doi.org/10.3386/w16841

Hertz, T., Jayasundera, T., Piraino, P., Selcuk, S., Smith, N., \& Verashchagina, A. (2008). The inheritance of educational inequality: International comparisons and fifty-year trends. The B.E. Journal of Economic Analysis \& Policy, 7(2). https://doi.org/10.2202/1935-1682.1775

Ho, E. S. (2010). Family influences on science learning among Hong Kong adolescents: What we learned from PISA. International Journal of Science and Mathematics Education, 8(3), 409-428. https://doi.org/10.1007/s10763-010-9198-3

Ho, E. S., \& Lau, K. (2018). Reading engagement and reading literacy performance: Effective policy and practices at home and in school. Journal of Research in Reading, 41(4), 657-679. https://doi.org/10.1111/1467-9817.12246

Hofstede, G., \& Bond, M. H. (1988). The Confucius connection: From cultural roots to economic growth. Organizational Dynamics, 16(4), 5-21. https://doi.org/10.1016/0090-2616(88)90009-5

$\mathrm{Hu}$, J. (2014). An analysis of the design process of a language learning management system. Control and Intelligent Systems, 42(1), 80-86. https://doi.org/10.2316/Journal.201.2014.1.201-2534

Hu, J., \& Wei, Y. (2019). The centrality of creativity: A new perspective on English language teaching. English Today, 35(2), 60-61. https://doi.org/10.1017/S0266078418000299

Hu, X., Gong, Y., Lai, C., \& Leung, F. K. (2018). The relationship between ICT and student literacy in mathematics, reading, and science across 44 countries: A multilevel analysis. Computers \& Education, 125, 1-13. https://doi.org/10.1016/j.compedu.2018.05.021

Jehangir, K., Glas, C. A., \& Van den Berg, S. (2015). Exploring the relation between socio-economic status and reading achievement in PISA 2009 through an intercepts-and-slopes-as-outcomes paradigm. International Journal of Educational Research, 71, 1-15. https://doi.org/10.1016/j.ijer.2015.02.002

Jin, Y., Li, B., Chen, N., Li, X., \& Hu, J. (2015). The discrimination of learning styles by bayes-based statistics: An extended study on ILS system. Control and Intelligent Systems, 43(2), 68-75. https://doi.org/10.2316/Journal.201.2015.2.201-2666

Jordan, M. I., \& Mitchell, T. M. (2015). Machine learning: Trends, perspectives, and prospects. Science, 349(6245), 255-260. https://doi.org/10.1126/science.aaa8415

Kern, M. L., \& Friedman, H. S. (2009). Early educational milestones as predictors of lifelong academic achievement, midlife adjustment, and longevity. Journal of Applied Developmental Psychology, 30(4), 
419-430. https://doi.org/10.1016/j.appdev.2008.12.025

Lee, V. E., \& Burkam, D. T. (2003). Dropping out of high school: The role of school organization and structure. American Educational Research Journal, 40(2), 353-393. https://doi.org/10.3102/00028312040002353

Leithwood, K., \& Day, C. (2008). The impact of school leadership on pupil outcomes. School Leadership \& Management, 28(1), 1-4. https://doi.org/10.1080/13632430701799718

Leithwood, K., Harris, A., \& Hopkins, D. (2008). Seven strong claims about successful school leadership. School Leadership \& Management, 28(1), 27-42. https://doi.org/10.1080/13632430701800060

Lenkeit, J., Caro, D. H., \& Strand, S. (2015). Tackling the remaining attainment gap between students with and without immigrant background: An investigation into the equivalence of SES constructs. Educational Research and Evaluation, 21(1), 60-83. https://doi.org/10.1080/13803611.2015.1009915

Li, X. F., Li, X. X., Li, Y. H., Yu, C. Y., Xue, W. W., Hu, J., Li. B., Wang, P. P., \& Zhu, F. (2019). What makes species productive of anti-cancer drugs? Clues from drugs' species origin, druglikeness, target and pathway. Anti-Cancer Agents in Medicinal Chemistry, 19(2), 194-203. https://doi.org/10.2174/1871520618666181029132017

Mak, S., Cheung, K., Soh, K., Sit, P., \& Ieong, M. (2016). An examination of student- and across-level mediation mechanisms accounting for gender differences in reading performance: a multilevel analysis of $\begin{array}{llll}\text { reading engagement. } & \text { Educational }\end{array}$ https://doi.org/10.1080/01443410.2016.1242712

Marks, G. N. (2005). Accounting for immigrant non-immigrant differences in reading and mathematics in twenty countries. Ethnic and Racial Studies, 28(5), 925-946. https://doi.org/10.1080/01419870500158943

McCluskey, C. P., Bynum, T. S., \& Patchin, J. W. (2004). Reducing chronic absenteeism: An assessment of an early truancy initiative. Crime \& Delinquency, 50(2), 214-234. https://doi.org/10.1177/0011128703258942

McKenna, M. C., Kear, D. J., \& Ellsworth, R. A. (1995). Children's attitudes toward reading: A national survey. Reading Research Quarterly, 30(4), 934. https://doi.org/10.2307/748205

Meng, L., Muñoz, M., King Hess, K., \& Liu, S. (2016). Effective teaching factors and student reading strategies as predictors of student achievement in PISA 2009: The case of China and the United States. Educational Review, 69(1), 68-84. https://doi.org/10.1080/00131911.2016.1155537

Ngorosho, D. (2010). Reading and writing ability in relation to home environment: A study in primary education in rural Tanzania. Child Indicators Research, 4(3), 369-388. https://doi.org/10.1007/s12187-010-9089-8

Nie, T., \& Hu, J. (2018). EFL students' satisfaction with the college English education in the MOOC: An empirical study. Advances in Social Science, Education and Humanities Research, 182, 92-95. https://doi.org/10.2991/iceemr-18.2018.19

OECD. (2010). PISA 2009 Assessment Framework: Key Competencies in Reading, Mathematics and Science. Paris, France: OECD Publishing. https://doi.org/10.1787/9789264062658-en

OECD. (2011). Singapore: Rapid improvement followed by strong performance. Lessons from PISA for the United States, 159-176. https://doi.org/10.1787/9789264096660-8-en

OECD. (2013). PISA 2012 Assessment and Analytical Framework: Mathematics, Reading, Science, Problem Solving and Financial Literacy. Paris, France: OECD Publishing. https://doi.org/10.1787/9789264190511-en

OECD. (2017). PISA 2015 Technical Report. Paris, France: OECD Publishing. https://doi.org/10.1787/9789264270282-en

Perera, L. D., \& Asadullah, M. N. (2019). Mind the gap: What explains Malaysia's underperformance in Pisa? International Journal of Educational Development, 65, 254-263. https://doi.org/10.1016/j.jjedudev.2018.08.010

Petko, D., Cantieni, A., \& Prasse, D. (2016). Perceived quality of educational technology matters. Journal of Educational Computing Research, 54(8), 1070-1091. https://doi.org/10.1177/0735633116649373

Poon, C. L., Lam, K. W., Chan, M., Chng, M., Kwek, D., \& Tan, S. (2016). Preparing students for the twenty-first century: A snapshot of Singapore's approach. Educating for the 21st Century, 225-241. https://doi.org/10.1007/978-981-10-1673-8_12

Reeve J. (2012). A self-determination theory perspective on student engagement. In S. Christenson, A. Reschly 
\& C. Wylie (Eds.), Handbook of Research on Student Engagement. Springer, Boston, MA. https://doi.org/10.1007/978-1-4614-2018-7_7

Reilly, D. (2012). Gender, culture, and sex-typed cognitive abilities. PLoS ONE, 7(7), e39904. https://doi.org/10.1371/journal.pone.0039904

Rutter, M., \& Maughan, B. (2002). School effectiveness findings 1979-2002. Journal of School Psychology, 40(6), 451-475. https://doi.org/10.1016/s0022-4405(02)00124-3

Sanz, H., Valim, C., Vegas, E., Oller, J. M., \& Reverter, F. (2018). SVM-RFE: Selection and visualization of the most relevant features through non-linear kernels. BMC Bioinformatics, 19, 1. https://doi.org/10.1186/s12859-018-2451-4

Schwabe, F., McElvany, N., \& Trendtel, M. (2015). The school age gender gap in reading achievement: Examining the influences of item format and intrinsic reading motivation. Reading Research Quarterly, 50(2), 219-232. https://doi.org/10.1002/rrq.92

Seneviratne, S., De Silva, L. C., Hu, J., \& Beveridge, J. (2019). Computer assisted language learning for syllable-time language exposed adults who are learning a new stress-time language. Proceedings of IEEE the 14th International Conference on Computer Science \& Education, Toronto, Canada. https://doi.org/10.1109/iccse.2019.8468845

Shin, S., Slater, C. L., \& Ortiz, S. (2017). Leader perceptions and student achievement. International Journal of Educational Management, 31(7), 1103-1118. https://doi.org/10.1108/IJEM-03-2016-0054

Sirin, S. R. (2005). Socioeconomic status and academic achievement: A meta-analytic review of research. Review of Educational Research, 75(3), 417-453. https://doi.org/10.3102/00346543075003417

Skryabin, M., Zhang, J., Liu, L., \& Zhang, D. (2015). How the ICT development level and usage influence student achievement in reading, mathematics, and science. Computers \& Education, 85, 49-58. https://doi.org/10.1016/j.compedu.2015.02.004

Smith, M. C., Mikulecky, L., Kibby, M. W., Dreher, M. J., \& Dole, J. A. (2000). What will be the demands of literacy in the workplace in the next millennium? Reading Research Quarterly, 35(3), 378-383. https://doi.org/10.1598/RRQ.35.3.3

Topçu, M. S., Arıkan, S., \& Erbilgin, E. (2014). Turkish students' science performance and related factors in PISA 2006 and 2009. The Australian Educational Researcher, 42(1), 117-132. https://doi.org/10.1007/s13384-014-0157-9

Van Hek, M., Kraaykamp, G., \& Pelzer, B. (2017). Do schools affect girls' and boys' reading performance differently? A multilevel study on the gendered effects of school resources and school practices. School Effectiveness and School Improvement, 29(1), 1-21. https://doi.org/10.1080/09243453.2017.1382540

Wei, Y., \& Hu, J. (2018a). A cross-sectional evaluation of EFL students' critical thinking dispositions in digital learning. Advances in Social Science, Education and Humanities Research, 195, 27-30. https://doi.org/10.2991/iserss-18.2018.8

Wei, Y., \& Hu, J. (2018b). The impact of the digital learning on EFL students' critical thinking disposition (pp. 644-647). Proceedings of IEEE the 13th International Conference on Computer Science \& Education, Sri Lanka. https://doi.org/10.1109/ICCSE.2018.8468755

Wei, Y., \& Hu, J. (2019). Differentiating critical thinking dispositions of newly enrolled EFL undergraduates and postgraduates through a support vector machine approach. Mechatronic Systems and Control, 47, 6976. https://doi.org/10.2316/Journal.201.2019.3.201-2979

Wei, Y., Yang, Q., Chen, J., \& Hu, J. (2018). The exploration of a machine learning approach for the assessment of learning styles changes. Mechatronic Systems and Control, 46(3), 121-126. https://doi.org/10.2316/Journal.201.2018.3.201-2979

White, K. R. (1982). The relation between socioeconomic status and academic achievement. Psychological Bulletin, 91(3), 461-481. https://doi.org/10.1037//0033-2909.91.3.461

Wolf, J. M., \& Bokhorst-Heng, W. (2008). Polices of promise and practices of limit: Singapore's literacy education policy landscape and its impact on one school programme. Educational Research for Policy and Practice, 7(3), 151-164. https://doi.org/10.1007/s10671-008-9048-z

Xiao, Y., \& Hu, J. (2019a). Assessment of optimal pedagogical factors for Canadian ESL learners' reading 
literacy through artificial intelligence algorithms. International Journal of English Linguistics, 9(4), 1-14. https://doi.org/10.5539/ijel.v9n4p1

Xiao, Y., \& Hu, J. (2019b). The influence of ICT attitudes on closing the reading literacy gap of students from different economic, social and cultural backgrounds. Proceedings of IEEE the 14th International Conference on Computer Science \& Education, Toronto, Canada. https://doi.org/10.1109/iccse.2019.8469547

Xiao, Y., \& Hu, J. (2019c). The moderation examination of ICT use on the association between Chinese mainland students' socioeconomic status and reading achievement. International Journal of Emerging Technologies in Learning, 14(15), 107-120. https://doi.org/10.3991/ijet.v14i15.10494

Xiao, Y., Li, Y., \& Hu, J. (2019). Construction of the Belt and Road Initiative in Chinese and American media: A critical discourse analysis based on self-built corpora. International Journal of English Linguistics, 9(3), 68-77. https://doi.org/10.5539/ijel.v9n3p68

Xiao, Y., Liu, Y., \& Hu, J. (2019). Regression analysis of ICT impact factors on early adolescents' reading proficiency in five high-performing countries. Frontiers in Psychology, 10, 1646. https://doi.org/10.3389/fpsyg.2019.01646

\section{Copyrights}

Copyright for this article is retained by the author, with first publication rights granted to the journal.

This is an open-access article distributed under the terms and conditions of the Creative Commons Attribution license (http://creativecommons.org/licenses/by/4.0/). 